\title{
$41919=$
}

\section{A imagem como ausência}

\section{Paulo Barroso}

\section{Resumo:}

Desde a Antiguidade Clássica Grega, com Platão a conceber a imagem como sombra, reflexo e, depois, como representação em geral, até à contemporaneidade, com o conceito aberto de "imagem" a adquirir novas formas virtuais de projeção de luz a incidir em suportes materiais como a água ou o ar, muito já se refletiu sobre a imagem, mas também sobre a sua conceção e papel no mundo contemporâneo, cada vez mais global, virtual e, principalmente, mais visual e iconólatra. Os novos meios e processos de produção e consumo de imagens demonstram um desenvolvimento visual. A imagem suscita o uso exagerado de dispositivos e meios de produção/reprodução de imagem e conduz a uma iconolatria moderna, que regista todos os domínios da vida humana: os mais privados (imagens íntimas publicadas nas redes sociais) e os mais públicos (fotojornalismo de guerra); os mais banais (selfies) e os momentos e situações mais únicos (ecografias); os mais credíveis e os mais manipulados pelo "arranjo" da imagem pelo Photoshop. Neste artigo, parte-se do pressuposto de que a imagem é um signo; possui o poder de transitividade semântica de evocar realidades e referentes ausentes ou inexistentes. Pretende-se sustentar a tese de que a imagem é, de um modo suficiente e necessário, uma imagem-signo e que o seu poder reside na função de representação que ocorre como uma hierofania, i.e. uma ausência latente que se manifesta, porque os significados da imagem estão ocultos ou codificados na própria imagem.

Palavras-chave: iconocracia; ideologia; imagem; poder da imagem; retórica.

\section{Abstract:}

Since Ancient Greece, with Plato's conception of image as, first of all, shadow, reflection and, then, as representation in general, to the present day, with the open-concept of "image" acquiring new virtual forms of light projection focusing on any material surface such as water or air, much has been reflected about the image, but also about its design 
and role in the contemporary world, which is increasingly global, virtual and, mostly, visual and iconolater. The new means and processes of production and consumption of images show a visual development. The image incites the overuse of devices and means of production/reproduction of image and leads to a modern iconolatry, which records all aspects of human life: the most private (intimate images published on social networks) and the most public (photojournalism of war); the most banal (selfies) and the unique moments and situations (echography); the most credible and the most manipulated by the "arrangement" of the image by Photoshop. I start from the assumption that an image is a sign; it has the power of semantic transitivity of evoking missing or non-existent realities and referents. My purpose is to support the thesis that image is sufficient and necessarily an image-sign and its power is in the representation function that occurs as a hierophany, i.e. a latent absence which manifest itself, because the meanings of the image are hidden or encoded in the image.

Keywords: iconocracy; ideology; image; power of image; rhetoric.

\section{Introdução}

A produção, reprodução e representação de imagens são processos culturais ancestrais, casuais ou intencionais, que cumprem necessidades humanas primordiais, como exprimir uma ideia. Compreende-se, deste modo, uma relação da imagem com o poder, i.e. o poder inerente de representação visual: manifestar ideias, crenças ou valores (e.g. místicos, religiosos, culturais, sociais, políticos, estéticos, etc.) e, assim, influenciar.

Se na Antiguidade Clássica Grega, Platão concebeu a imagem como sombra, reflexo e, depois, como representação em geral, na contemporaneidade, o conceito de "imagem" torna-se cada vez mais aberto e adquire, por exemplo, novas formas virtuais de projeção de luz a incidir sobre qualquer suporte material como a água ou o ar. Desde o tempo de Platão que muito já se refletiu sobre a imagem, mas também sobre a sua conceção e papel no mundo contemporâneo, cada vez mais global, virtual e, principalmente, mais visual e iconólatra. Os novos meios e processos de produção e consumo de imagens demonstram um desenvolvimento visual. A imagem suscita o uso exagerado de dispositivos e meios de produção/reprodução de imagem e conduz a uma iconolatria moderna, que regista os domínios da vida humana, dos mais privados (imagens íntimas publicadas nas redes sociais) aos mais públicos (fotojornalismo de guerra); dos mais banais (selfies) aos momentos e situações mais únicos (ecografias); dos mais credíveis aos mais manipulados pelo "arranjo" da imagem pelo Photoshop. 
Parte-se do pressuposto de que a imagem é um signo; possui o poder de transitividade semântica em evocar realidades e referentes ausentes ou inexistentes. O objetivo deste texto é sustentar a tese de que a imagem é, de um modo suficiente e necessário, uma imagem-signo e que o seu poder reside na função de representação que ocorre como uma hierofania, i.e. uma ausência latente que se manifesta, porque os significados da imagem estão ocultos ou codificados na própria imagem.

\section{O poder da imagem}

Uma imagem é uma presença que se manifesta e que desvela o visível. Mas também é, antes de ser uma presença, uma ausência, um paradigma, conforme o sentido etimológico grego de paradeigma ("padrão", "modelo") e paradeiknumi ("expôr", "representar", i.e. "mostrar lado a lado"). Enquanto ausência ou paradigma, a imagem não deixa ver o que mostra ou o que revela, porque se encontra no plano ou eixo das relações entre as unidades de significação presentes e ausentes. O que uma imagem torna visível é o que está presente (expressão sensível) e o que está ausente (conteúdo inteligível). Enquanto eixo de relações entre as unidades de significação, uma imagem é um signo. Por conseguinte, uma imagem possui o poder de transitividade semântica, i.e. o poder de evocar realidades e referentes ausentes ou inexistentes. A imagem, enquanto imagem-signo, conta com a simples manifestação, que é propriedade inerente à imagem. A manifestação (do Latim manifestare, "descobrir", "revelar", "denunciar", "expor", "patentear", enfim "tornar visível") da imagem é interpretada no sentido de "revelação", "des-velamento" ou “des-ocultação" do (in)visível que está na imagem.

Para manifestar, expressar ou significar, são necessários signos, i.e. artefactos culturais com significados. A imagem, tal como o signo, significa sempre mais do que aquilo que mostra num primeiro sentido denotativo. Significa profundamente o seu enquadramento numa estrutura de significação, em que um sentido direto designa, por acréscimo, um outro sentido indireto que apenas pode ser apreendido através do primeiro. É nesta perspetiva que, para Paul Ricoeur, o símbolo (uma das sub-classes de signos) significa mais do que aquilo que mostra, na medida em que o símbolo nunca vale por si mesmo; vale pelo que indica, representa ou faz pensar. O símbolo diz sempre mais do que aquilo que mostra, porque "em última instância, todo o símbolo é uma hierofania" (Ricoeur, 2013: 373). Se a imagem é uma imagem-signo e se a imagem conta em particular com o simples e inerente poder de manifestar, a imagem é uma hierofania (do grego hieros, "sagrado", e phanein, "manifestar") em que, como todo o símbolo, faz aparecer o sentido como uma manifestação do sagrado, na mesma perspetiva usada por Mircea Eliade em O Sagrado e o Profano - A Essência das Religiões (1999: 25). Enquanto hierofania, a 
imagem é uma ausência latente que se manifesta, porque os significados da imagem estão ocultos ou codificados na própria imagem.

A produção, reprodução e representação de imagens são processos culturais ancestrais, casuais ou intencionais, que cumprem funções humanas primordiais, como a simples necessidade de exprimir uma ideia. Através da função da imagem em satisfazer necessidades básicas, reconhece-se uma relação da imagem com o poder inerente à própria imagem, i.e. o poder de representação visual. O poder da imagem em manifestar ideias, crenças ou valores (e.g. místicos, religiosos, culturais, sociais, políticos, estéticos, etc.) e, deste modo, influenciar os outros. Como são processos ancestrais, sobre a imagem já muito se teorizou. Desde a Antiguidade Clássica Grega, com Platão a conceber a imagem, primeiro, como sombra, reflexo e, depois, como representação em geral. Esta conceção de "imagem" para Platão é ambígua, mas apresenta-se como um primeiro esboço demonstrativo da componente representacional de qualquer imagem: "Chamo imagens, em primeiro lugar, às sombras; em seguida aos reflexos nas águas ou à superfície dos corpos opacos, polidos e brilhantes e todas as representações deste género" (Platão, 2006: 509e-510a).

Uma imagem é um sistema de significação e de comunicação diferente do sistema da linguagem falada ou escrita. Uma imagem é sempre uma representação (figurativa ou abstrata, consciente ou inconsciente, intencional ou não) de alguma coisa. Uma imagem é uma representação que, como tal, serve de substituto ou recriação da realidade. Uma imagem é um artefacto; é o resultado de uma produção (intenção) e/ou receção (perceção). O sentido em que é usada a palavra "imagem" significa "imagem feita pelo ser humano". Na condição de signo/representação que manifesta necessariamente algo, a imagem é potência de representação (no sentido de repraesentatio, repraesentare, "tornar presente", "reapresentar", cabendo nesta terminologia qualquer imagem destinada a tornar sensíveis objetos, factos ou ações ausentes ou impossíveis de mostrar tal qual são).

Apesar de não remeter sempre para o visível, a imagem toma de empréstimo alguns traços ao visual e depende do processo de produção: imaginária ou concreta, material ou intangível, a imagem passa por alguém, que a produz ou a reconhece como tal. É uma transitividade aliquid pro aliquo; assemelha-se a algo e, por isso, não é esse algo que representa e evoca. Evocar é uma das principais características da imagem, porque uma imagem é algo que se assemelha a qualquer outra coisa (Joly, 2008: 42). Se a imagem se assemelha a qualquer outra coisa, então a imagem não é (nem pode ser) essa coisa. A função da imagem é a de evocar e significar outra coisa que não ela própria, utilizando o processo da semelhança. A imagem é, por conseguinte, uma representação, i.e. um signo, um produto cultural, em que o que é visto e o modo como 
se vê são ambos culturais. Uma imagem estabelece uma vista, uma aparência que corporiza um modo de ver. A imagem mostra e oculta significados de um modo estratégico, i.e. o uso da imagem subjaz ao uso da imagem como potência, que é capaz de cumprir a pretensão de mostrar (dependendo do que se mostra e do modo como se mostra). Todas as imagens sugerem modos de ver. Segundo John Berger, uma imagem é uma vista que foi recriada ou reproduzida; é uma aparência que foi "isolada do local e do tempo em que primeiro se deu o seu aparecimento" (Berger et al., 2005: 12).

O poder da imagem reside, por conseguinte, na possibilidade de se permitir a manifestação de algo, o referente congénito da imagem. A imagem exige a sua presença para exercer o poder de representação. Mais do que uma coisa ou um objeto, a imagem vale pelo que não é, i.e. vale pela sua representação de uma outra coisa. $O$ poder da imagem está na possibilidade de a imagem ser percebida e frutificar num ato de consciência; não está em a imagem consistir numa coisa, o que a confundiria com a coisa que a imagem representa. É como disse Régis Debray (1994: 299): tudo está na tela e "o mundo tornou-se, com efeito, minha representação". A expressão "tudo está na tela" é explicada pelo idealismo absoluto do Esse est percipi de Berkeley, que se alastrou no espaço público através dos dispositivos tecnológicos de visibilidade. A essência da realidade, de tudo o que existe, está em ser percebido por nós através das suas imagens.

A expressão "o mundo tornou-se a minha representação" é justificada pela segunda e mais importante possibilidade de conceção do mundo para Schopenhauer, a de o mundo como representação, i.e. ilusão, aparência (Schopenhauer, 2005: 74). Se o mundo se tornou a minha representação é porque o mundo como representação é o mundo das coisas como nos são propostas e nos aparecem numa configuração ordenada e estruturada previamente, como acontece com as imagens. Em o mundo como representação de Schopenhauer, o nível de significação é o da representação, que é precisamente a visibilidade do que nós vemos, a imagem que possuímos, porque todas as nossas representações são representações de representações conforme os princípios que estabelecemos.

A propósito da imaterialidade da imagem, esta é, para Sartre (s.d.), um ato de consciência e não uma coisa. Sartre não concorda com o "coisismo das imagens", mas explica esta perspetiva: “as coisas estão continuamente a emitir 'simulacros', 'ídolos' que são meros invólucros. Estes invólucros têm todas as qualidades do objecto, conteúdo, forma, etc. São mesmo, exactamente, objectos" (Sartre, s.d.: 10). Estes objetos ou coisas que são as imagens adquirem existência em si mesmos quando são emitidos, suscitando perceções dos aparelhos sensíveis. Em rigor, a imagem não é uma coisa na perspetiva de Sartre, porque tem uma inferioridade metafísica relativamente à 
coisa que representa, mas os dados da intuição incorporam-se na construção teórica sob uma forma nova e a imagem é compreendida como uma coisa (ou "coisa menor" com existência própria e que se oferece à consciência como qualquer outra coisa, mantendo relações externas com a coisa de que é imagem), tanto quanto a coisa de que é imagem (Sartre, s.d.: 10).

Esta perspetiva pura e a priori sobre a imagem é limitada e discutível, devendo-se melhor ter em conta as advertências de Sartre, que segue uma espécie de ontologia da imagem e distingue a identidade de essência e a identidade de existência da imagem, salientando a importância da experiência e das relações da imagem com o pensamento. A imagem nunca está isolada porque faz parte de um sistema semiótico de imagenssignos, sendo compreendida através deste sistema. Trata-se de um complexo de significantes e significados, o sensível e o inteligível, a intenção e o reconhecimento. Mas a imagem dos discursos públicos (e.g. dos partidos políticos ou dos media) é um signo construído pela retórica; um signo que é tornado compreensível pelos sistemas e as formas de cultura. A imagem é, como disse Sartre (s.d.: 75) a este propósito, "uma rampa que impede o pensamento de descair para fora do seu caminho, mas às vezes é também uma barreira a impedir o caminho".

Em A Imagem, Jacques Aumont associou a imagem necessariamente à visão, quando afirmou que as imagens são feitas para serem vistas. A visão não é um instrumento neutro que se limita a transmitir dados do modo mais fidedigno quanto possível, mas um dos pontos de encontro do cérebro do espectador com o mundo (Aumont, 2002: 77). Nesse encontro entram em jogo a capacidade percetiva; o saber; os afetos; e as crenças (relativas ou variáveis históricas).

O poder da imagem está subjacente à forma como nos relacionamos com as imagens, quer de um modo consciente quer de um modo inconsciente. Esse relacionamento está explanado nas seguintes quatro questões: 1) Por que se olha uma imagem? 2) Para que servem as imagens? 3) O que nos transmitem as imagens? 4) Como são (ou devem ser) olhadas?

Quando olhamos para uma imagem, a nossa visão é sempre orientada pela interpretação contextual. É o que Wittgenstein denomina por "formas de vida", i.e. modos de ver (Wittgenstein, 1996: 19 e 23). O poder evocativo de uma imagem não é o mesmo para todos, porque diferem as experiências e contextos próprios de cada pessoa que a recebe e a interpreta de forma diferente. Roland Barthes designa por studium a influência cultural, política, religiosa e histórica de que o observador é alvo ao observar uma fotografia e por punctum o "algo" na fotografia que leva o observador a ter uma emoção mais forte por ver essa fotografia (Barthes, 2006: 34). 
É o que acontece, por exemplo, com as imagens de guerra, que estimulam impulsos morais através de arquétipos e se tornam mais memoráveis. As imagens de guerra são registos de momentos privilegiados convertidos num suporte que permite conservar 0 olhar. Como na célebre fotografia da Guerra do Vietnam, registada em 1972 por Huynh Cong, da Associated Press, a imagem contribui mais para "aumentar o repúdio do público pela guerra do que cem horas de atrocidades televisionadas", segundo Susan Sontag (2012: 26). É a nossa "consciência política" e o nosso grau de familiaridade com as imagens, segundo Susan Sontag, que "determina a possibilidade de sermos moralmente afectados por fotografias" dos oprimidos, explorados, esfomeados e massacrados que nos sensibilizam.

A banalidade da imagem faz diminuir o seu impacto. Fotografias muito conhecidas familiarizam-nos com a atrocidade, "fazendo com que o horrível pareça vulgar, familiar, remoto" (Sontag, 2012: 29). É neste sentido que Susan Sontag fala no frágil conteúdo ético das fotografias. Quando as imagens (fotografia ou vídeo) mostram os rostos em sofrimento de vítimas inocentes, certas causas surgem como mais prementes.

Num mundo dominado pelas imagens fotográficas, o serviço informativo e denunciador prestado por fotografias deste género tornam-nas objetos simbólicos ou simulacros de conhecimentos, "tal como o acto de fotografar é um simulacro de apropriação" (Sontag, 2012: 30). "As sociedades industriais transformam os seus cidadãos em viciados de imagens; trata-se da mais irresistível forma de poluição mental. [...] Hoje em dia, tudo o que existe, existe para acabar numa fotografia" (Sontag, 2012: 32). Concebida como espetáculo para as massas, a imagem e a sua produção fornecem uma ideologia dominante.

i. Por conseguinte, sintetizam-se assim as respostas às perguntas anteriores:

ii. Olha-se para uma imagem porque a imagem é presença de uma ausência; chama a atenção e manifesta visualidade, revela algo além de si mesma;

iii. As imagens servem para manifestar, exprimir, representar ou evocar os respetivos referentes, o que quer que seja o conteúdo da imagem;

iv. O que nos transmitem as imagens é sempre relativo ao que as imagens contêm e como expressam o seu conteúdo, em função das ideias, valores ou crenças que veiculam os mitos ou ideologias que as incorporam;

v. O modo como as imagens são olhadas não é necessariamente correspondente ao modo como devem ser olhadas, porque ambos os modos são ditados pela retórica visual com que as imagens são "trabalhadas", apresentadas e percecionadas.

Ao cumprir a função de significação, de comunicação ou de persuasão, uma imagem tem de ser, previamente, concebida e fabricada com intencionalidade. Segundo 
Jacques Aumont (2002: 78), a produção de imagens nunca é gratuita; pelo contrário, as imagens são fabricadas para determinados usos individuais ou coletivos, como os de informação, expressão artística, propaganda ou ideologia. Mas uma das razões essenciais da produção da imagem, segundo Jacques Aumont, provém da vinculação da imagem com o domínio do simbólico, o que faz com que ela esteja em situação de mediação entre o espectador e a realidade. Enquanto representação, uma imagem é um veículo ou suporte de transmissão de informações e reflete valores sociais, princípios morais, padrões culturais, etc. de determinada sociedade/época. É desta condição ou propriedade da imagem que advém o seu poder e que se expande esse poder na forma de uma iconocracia.

\subsection{Iconocracia}

A iconocracia é o poder (cracia) das imagens (icono). Nas sociedades atuais, este poder exige uma maior educação para as imagens. A quantidade de imagens que nos rodeia e capta a nossa atenção é cada vez maior. Segundo Susan Sontag, desde 1839, momento em que a tecnologia tornou possível a crescente difusão de uma mentalidade que vê o mundo como um conjunto de potenciais fotografias, que quase tudo parece ter sido fotografado como se tratasse de uma "insaciabilidade do olhar fotográfico" que nos impõe ou ensina um novo código visual (Sontag, 2012: 11). É como a democratização de todas as experiências traduzidas para imagens. Para Susan Sontag, as imagens fotográficas transformam e ampliam as nossas noções sobre o que vale a pena olhar e do que pode ser observado. As fotografias são uma gramática; uma "ética da visão" (Sontag, 2012: 11). As fotografias são experiências capturadas, segundo Susan Sontag, e a câmara é o instrumento ideal da consciência nessa aquisição. Nos usos populares da fotografia (relacionados com a celebração da família num casamento ou com o turismo, em que a fotografia comprova a experiência por via da recordação), a imagem é uma pseudo-presença e um signo de ausência.

A massificação dos discursos públicos, essencialmente visuais, revela uma nova iconolatria que se confunde com uma iconocracia, i.e. um poder autocrático da imagem que impõe o visível ou o que tem de ser visto. É o predomínio e prepotência dos signos visuais, das imagens e das retóricas das imagens. Impõe-se a imagem ao olhar público, uma ordem da visibilidade, uma disciplina sobre a perceção visual. O espaço público moderno, principalmente cosmopolita, transforma-se numa iconosfera devido à ubiquidade, plêiade ou pletora das imagens; uma saturação que indisciplina e confunde o olhar. A iconosfera é a "era do visual". É a primazia da imagem, a prevalência do visível nas formas de vida/cultura populares e visuais. 
A iconolatria ou esplendor da imagem foi devidamente salientado por Guy Debord (1995: 12), para quem "toda a vida em sociedade é, em si, uma acumulação de espectáculos, uma concreta inversão da vida e, como tal, o movimento autónomo da não vida que, sendo verdade, é representada como falsa". Segundo o autor, existe uma função do espetáculo na sociedade, que é a "concreta produção de alienação" (Debord, 1995, 23). Esta perspetiva torna-se ainda mais pertinente e acurada por ter sido subscrita por Gilles Deleuze (1985: 20), quando este usou a denominação de "civilização de imagem". Para Deleuze, esta civilização da imagem é, sobretudo, uma "civilização do cliché", i.e. uma civilização da inflação icónica que assenta na redundância e na ocultação (do poder de persuasão), distorção ou manipulação.

Assim, existe uma generalizada "felicidade tribal do "cliché", conforme reconheceu Régis Debray (1994: 299); um contentamento pelo lugar-comum, que é a imagem publicitária. Vestígios da civilização da imagem residem em contextos onde se verifica uma hegemonia de imagens suficiente e necessária para o rótulo de "cultura do ecrã" ou "paradigma visual". Por exemplo, em Times Square, Nova lorque, a imagem publicitária é tão marcante e presente que constitui parte da identidade do próprio espaço público. Neste local, identifica-se o poder da imagem enquanto dispositivo específico da cultura de massas.

Todavia, três paradoxos caracterizam a iconocracia da publicidade: a) a banalidade da imagem publicitária enfraquece o seu impacto percetivo e o seu poder persuasivo, porque a perceção do espectro cromático da imagem se baseia em princípios simbólicos, culturais (o paradoxo é que a mesma cultura que padroniza a perceção da imagem também retira o poder da imagem ao ser cultura de massas); b) o poder da imagem até nem está tanto na sua visibilidade, mas mais na ocultação de sentidos (revela sem mostrar); c) as imagens não sugerem um produto (bem, serviço ou marca), mas uma lacuna, uma falta, uma necessidade nos consumidores.

\subsection{Retórica da imagem no espaço público}

A estrutura das culturas atuais assenta no paralelismo entre o antigo (tradição) e o moderno (inovação). Este paralelismo contribui para a ressemantização ou reconversão do "antigo", segundo Roland Barthes em A Aventura Semiológica. Barthes (1987: 19) referia-se à designada "retórica antiga" face ao moderno como o que "ainda não existe" e como a se esconder sempre a partir de e contra alguma coisa, ao afirmar que "o mundo está incrivelmente cheio de retórica antiga". Por isso, a retórica é "uma arte essencialmente republicana", segundo Nietzsche (1995: 16 e 27); uma arte republicana no sentido em que está à disposição da res pública, está ao alcance de todos para que todos participem e intervenham no espaço público e legitimem as suas pretensões. 
Não existe poder sem formas de expressão do poder nem formas de reconhecimento e de pretensão sobre a legitimação do poder. A retórica é a principal destas formas, porque é uma meta-linguagem multifuncional; uma meta-linguagem cuja linguagemobjeto é o discurso e é, tal como a poética, um discurso sobre o discurso, que comporta várias práticas, como uma técnica ou arte da persuasão, um ensino, uma ciência ou proto-ciência, uma moral e uma prática social, para Roland Barthes (1987: 20). A retórica é uma técnica de linguagem estratégica e conveniente. É utilizada de uma forma aprimorada ou capacitada, persuasiva e intencional. É a arte de expressão segundo determinados usos, tornando-se mais eficaz e sedutora para a obtenção de objetivos e, por isso, está implicada nos resultados pragmáticos da comunicação.

A retórica, enquanto demonstração da verosimilhança, é uma técnica recorrente dos discursos públicos, que também seguem estratégias de proximidade como o verosímil, o que parece ser verdadeiro, crível, provável, i.e. seguem estratégias de manipulação através das aparências tornando-se desejável pelo modo de argumentação. A retórica surge como demonstração da verosimilhança por meio da prova, segundo o Ménon de Platão (1992: 273d). Implica-se a noção de um raciocínio retórico (argumentativo) que não ensina a verdade, como acontece com a epistemé, mas apenas uma aproximação à verdade, uma verosimilhança modificável no tempo e no espaço (doxa). A retórica, em particular a retórica visual, demonstra a verosimilhança, a aparência e a proximidade convenientes, mas falsas.

Aplicada aos discursos públicos, a retórica explora a visualidade da imagem e potencia os efeitos de persuasão da mensagem. A retórica torna-se visual, porque se centra na imagem que faz funcionar como uma linguagem apelativa, cuja unidade significante não é a palavra, mas a imagem. A virtude da imagem é que esta não se vê em chinês, árabe ou inglês, porque simplesmente vê-se, segundo Giovanni Sartori (2000: 27). A imagem, enquanto imagem-signo ou hierofania, constitui-se no que possui de essencial: a simples manifestação do seu conteúdo. A visibilidade da imagem exige, por conseguinte, apenas $\mathrm{o}$ ato de ver e, por isso, a imagem fotográfica é, para Roland Barthes, uma mensagem sem código (2009: 13). Este é o paradoxo fotográfico para Roland Barthes: todas as linguagens possuem código (esta é uma condição essencial e indispensável para serem linguagem); a fotografia é uma linguagem; mas a fotografia não possui código. Isto deve-se ao facto de a fotografia ser uma mensagem contínua e dispensar código; a imagem fotográfica é de leitura e interpretação do que ela representa, pois a mesma revela o seu conteúdo; basta olhar e ver. Susan Sontag (2012: 12) chama a esta veracidade objetiva da imagem de "simples transparência selectiva". 
Os discursos públicos trabalham a imagem tornando-a um recurso retórico eficaz. Através de técnicas sofisticadas de linguagem (e.g. recursos estilísticos), a prática da imagem revela-se uma prática de comunicação estratégica e ardil em manifestar (e convencer sobre) o que se pretende. A capacidade de manifestação cultural e a componente expressiva ou significante desta prática e técnica devem-se aos meios de comunicação, mas também ao trabalho sobre a visualidade das mensagens.

Nas sociedades contemporâneas e ocidentais, a globalização transforma, por um lado, a prática da imagem, tornando-a num fenómeno social baseado em processos e dispositivos tecnológicos, por outro lado, as formas de vida/cultura, cada vez mais uniformes, populares e visuais. Os efeitos mais notórios destas transformações são o predomínio dos meios e dos discursos públicos, ambos centrados na produção, reprodução e representação de imagens capazes de influírem e de se disseminarem no espaço público.

Com a globalização, também o espaço se transforma num campo uniformizado e alargado de produção e de consumo. Os meios e os discursos públicos produzem, reproduzem e representam imagens de uma forma tautológica e, por isso, também moldam o espaço público, tornando-o tautológico.

O espaço é um fator de identidade social e cultural. O espaço não é apenas uma realidade social específica; também afirma relações de identidade entre as pessoas e entre estas e o próprio espaço. Nesta perspetiva, o espaço é um constructo social e material, mas também é um constructo conceptual: é uma categoria de entendimento e pensamento coletivo. O espaço cria relações e uma memória coletiva; permite, por conseguinte, a adaptação do Ser ao espaço, condicionando as características do próprio Ser.

O espaço público é um território ideológico; manifesta valores sociais e padrões culturais. O uso de imagens no espaço público é o uso de estratégias, dispositivos retóricos modernos e discursos com orientações, sugestões, seduções e apelos a um determinado estilo de vida. O apelo da modernidade incide nos discursos de massas e de consumo através de estratégias de sedução e provocação de desejos, como acontece com as imagens de publicidade em outdoors ou mupis. Neste campo da sedução, a retórica das imagens publicitárias é paradigmática, na medida em que constrói o espaço público através de suportes visuais de transmissão de mensagens, i.e. a construção de um ecossistema cultural ideológico.

$\mathrm{Na}$ comunicação estratégica, a imagem é usada como um meio ardiloso, apodítico e epidíctico. A utilização de técnicas de retórica visual potencia os efeitos das imagens e dos discursos públicos que as incorporam. A exploração retórica da visualidade das imagens potencia a eficácia das mensagens. Qualquer tipo de elemento figurativo 
transforma-se em retórica visual, i.e. em forma de comunicação que usa imagens para criar significados ou construir argumentos (Bulmer \& Oliver, 2006: 55). Por isso e também devido à ubiquidade dos ecrãs enquanto responsáveis por uma "nova espécie humana" (o homo videns, de Giovanni Sartori) ou uma nova era (a "civilização da imagem", de Enrico Fulchignoni) a imagem adquiriu um centralismo nos usos e práticas sociais de transmissão de informações, tornando o visual ou a visualidade mais importante do que a própria visão.

Pela eficácia da visualização, as imagens criam outros significados (culturais) aos já existentes, camadas de significados que são retirados dos seus contextos próprios, originais, e que são transformados ou ressemantizados na imagem que se pretende reproduzir "de um certo algo" para "um outro algo". Esta mudança de significados e camadas de significados torna um discurso público imagético numa meta-linguagem, num dispositivo mitopoiético e logopoiético, i.e. de produção de polissemia através da linguagem/imagem.

O poder da imagem é proporcional às culturas mais visuais e populares, onde proliferam ecrãs e imagens. Esta circunstância caracteriza a atual iconolatria. Mas até que ponto as imagens publicitárias constroem a cultura e o simbolismo (valores e imaginários sociais; memória e identidade coletivas) nos espaços urbanos? Por outras palavras, as imagens da publicidade no espaço público dizem quem somos/devemos ser e como vivemos/devemos viver? O ideal imagético publicitário tiraniza? Quais são as consequências das transformações para a (re)produção de valores e imaginários sociais? Qual é a relação entre a ubiquidade da comunicação visual, na forma de uma retórica visual iconocrática, e a massificação, secularização e ressemantização do espaço público?

A retórica da imagem transforma a publicidade numa linguagem da "orto-doxia" sobre desejos e sensações, em que o poder da imagem é o poder de transferir significados e criar camadas de significados. Por esta via estetizante da imagem, usam-se as estruturas ou elementos estéticos (formas, sombras, cores, saturação, profundidade, movimento, iconocidade, etc.) e semânticos (níveis de codificação: icónico, iconográfico, tropológico, tópico e entimemático), constituindo-se uma expressão retórica visual. 0 design e a conotação da imagem estetizam o visual e transferem significados ao referente da imagem. A importância adquirida pela imagem nas sociedades contemporâneas centra-se não apenas na quantidade de ecrãs no espaço público, mas também nos efeitos semânticos e performativos (sobre os públicos) do uso da retórica visual pelos discursos públicos. É neste sentido que se identificam no espaço público moderno (principalmente no urbano, cosmopolita e massificado) um excesso e 
predomínio de imagens publicitárias (e.g. outdoors, mupis, etc.), o que demonstra a iconofilia e a cultura visual.

Régis Debray (1994: 241) refere-se à identidade entre o signo e a imagem como um "rebaixamento das imagens para simples signos", devido à "passagem do reclame (gabar as qualidades de um objecto) para a publicidade (lisonjear os desejos de um sujeito)". Independentemente desta interpretação de Régis Debray, as imagens são signos, i.e. são uma sub-classe de signos denominada "ícone" e que suplantou uma outra sub-classe de signos: a palavra. Enquanto esta última era dominante nas manifestações culturais mais remotas, o ícone é preponderante nas atuais formas de cultura visual. Pela primeira vez, a palavra do ano 2015 dos dicionários Oxford (escolhida por melhor representar os sentimentos ou as preocupações gerais) é pictográfica: um emoji.

As imagens publicitárias estão omnipresentes no espaço público; são numerosas e visam essencialmente persuadir. No espaço público, a imagem é, regra geral: a) totalitária, porque cria intencionalmente o pressuposto de ser percecionada como proposta desinteressada e interlocução para a verdade conveniente do público; b) hiperbólica, porque amplifica a mensagem através de formas e conteúdos exagerados, como enormes ecrãs e figuras de retórica; c) tautológica, porque estrategicamente repete as formas e conteúdos para enfatizar a mensagem a reter pelo público); d) ideológica, porque veicula valores, ideias ou interesses particulares.

A exploração de imagens publicitárias no espaço público revela a preocupação com o aproveitamento da visibilidade. Segundo Jean Baudrillard (1991: 116), a realidade cumpre-se como signo, representação, i.e. simulacro, artifício. A imagem é adaptada para possuir a capacidade de influenciar o inconsciente humano e estimular desejos. $O$ público compra o produto, mas consome o signo, como advertiu Baudrillard.

\subsection{Retórica e ideologia: o lugar do mito}

As imagens pertencem a estruturas de sentido e, nesta base, são usadas em publicidade para obter efeitos de persuasão. Ao se apoiarem em sistemas de sentido já existentes, as imagens publicitárias afirmam determinados modelos sociais e possuem, segundo Ugo Volli (2004: 11), um forte cunho ideológico. Para Roland Barthes, há um ponto comum para o qual remetem todos os sistemas conotativos: a ideologia. Quer isto dizer que todos os significados das conotações desembocam na ideologia ou, mais exatamente, "a ideologia é a forma dos significados de conotação" (Barthes, 2007: 77). Em contrapartida, a retórica é a forma dos conotadores. Compreender os mecanismos da retórica visual nos anúncios publicitários é compreender as formas de significação e o papel desideologizante da cultura. A ideologia encontra-se sempre num segundo 
sentido, mais ou menos escondida, e a compreensão dos mecanismos da retórica deve expor os sistemas semiológicos pelos quais é produzida e em que existe.

A função da ideologia através dos discursos públicos, como a publicidade, é construir indivíduos enquanto sujeitos, i.e. "sujeitos sujeitados" pela interpelação ideológica. A publicidade dirige-se a sujeitos ideológicos, mas sujeitados, estando a ideologia subjacente ao enunciado (texto ou imagem).

A publicidade faz da imagem um signo que tem de ser compreendido e esta imposição relaciona a imagem (significante exterior) com o pensamento (significado na mente), i.e. a imagem-signo com a imagem-perceção. A imagem, enquanto objeto percebido (a imagem-signo), impõe-se ao pensamento (imagem-perceção) e regula as ideias; serve para decifrar, compreender, explicar. Percebemos imagens exteriores e formamos imagens mentais para concebermos esquemas ou mapas conceptuais interpretativos de um mundo codificado e eivado de imagens. Todas as imagens são significações culturais inseridas num sistema.

A retórica visual segue uma gramática estilística peculiar, pois os requisitos são sempre cumpridos para garantirem a performatividade desejada: a formação, transmissão e representação de um significado mítico, que associa a marca e/ou o produto, o estereótipo de beleza feminina e o prazer sensual exótico, i.e. associa-se a marca e/ou o produto comercial, o significado mítico reproduzido e as emoções que o anúncio pretende suscitar no público. Por exemplo, a inusitada nudez de uma mulher numa imagem de outdoor provoca sex appeal e contrasta com o espaço público urbano, por vezes caótico, onde o prazer sensual exótico é suscitado. Essa nudez feminina não é apenas um signo que denota uma pessoa; a imagem da modelo é também um signo com conotações, tais como "juventude", "magreza", "saúde", etc., i.e. conceitos que pertencem ao stock de mitos positivos da sociedade e estão relacionados com os atributos das mulheres sexualmente desejáveis. Este signo tem estas conotações positivas; pode funcionar como significante para o significado mítico "beleza feminina". Este conceito de beleza é o que Roland Barthes descreve como um significado mítico (Bignell, 2002: 33). Deste modo retórico, a publicidade produz e reproduz ideologias relacionadas com conceitos e valores sociais.

O poder da linguagem (verbal ou não verbal) é o poder da imagem nos três sentidos que Platão mencionou no Fedro: a) remédio; b) veneno; e c) cosmético (Platão, 2000: 274e). Segundo esta perspetiva de Platão, a linguagem pode ser conhecimentocomunicação, mas também pode ser encantamento-sedução (Derrida, 2005: 44). Esses poderes da linguagem (conhecimento, sedução e máscara da verdade) são devidos à capacidade e à forma de transmissão de significados, explorando-se técnicas de persuasão e estratégias de cultivo de modos de pensar, de engodo dos desejos (Volli, 
2004: 39). Assim, nesta época de informação eletrónica domina o homo videns e o "videoviver" de Giovanni Sartori, em que "o vídeo está a transformar o homo sapiens, produto da cultura escrita, em homo videns, no qual a palavra é destronada pela imagem" (Sartori, 2000: 13). A primazia da imagem (i.e. a prevalência do visível sobre o inteligível) leva a um "ver sem compreender" (Sartori, 2000: 14).

As formas de vida/cultura populares e visuais são, por norma, ideológicas. O que se consome nestas formas de vida/cultura incorpora ideologia, quer seja nos próprios produtos, incluindo os culturais, quer seja nas mensagens que interpelam ao consumo desses produtos. Estas formas de vida/cultura implicam o não conhecimento dos seus participantes sobre a sua essência, que não sabem o que fazem. É este o essencial sentido de "ideologia", enquanto distorção da visão sobre a realidade. A dimensão fundamental da ideologia é a que a torna não apenas uma "falsa consciência", uma representação ilusória da realidade, mas uma falsa consciência misturada com a própria realidade. Segundo Slavoj Zizek, em The Sublime Object of Ideology, é "essa mesma realidade que já está preparada para ser concebida como 'ideológica'” (2008: 15). É esta dimensão que caracteriza e faz funcionar a própria ideologia.

A ideologia é como um imaginário social ideal, uma conceção e uma prática cultural e social dotada de eficácia que pretende transformar a perceção do ser humano sobre o mundo. No contexto da teoria marxista, o conceito de "ideologia" tem o sentido de "falsa consciência" por mascarar as relações com a realidade, onde é fundamental para o processo de clarificação crítica e racional da consciência, de modo a se superar a falsa consciência que o indivíduo possui (Ricoeur, 1991: 175-177).

Esta definição de ideologia pode suscitar uma interpretação positiva (i.e. a ideia de ideologia como orientação para o pensamento e ação e como inspiração motivadora para a vida) e outra negativa (i.e. a conceção da ideologia como conjunto de ideias que fornece uma imagem ou representação falsa ou destorcida da realidade e das circunstâncias da vida social) (Ricoeur, 1991: 66-68). Por um lado, a ideologia é identificada com a superestrutura, por outro lado, é vista apenas como parte dessa superestrutura. Em A Ideologia Alemã, a ideologia é um reflexo invertido do real na consciência das pessoas que vivem em sociedade sobre a natureza das suas relações, como acontece com a inversão das imagens numa câmara escura (Marx \& Engels, 1982: 14). Sendo um reflexo invertido ou uma fantasmagoria, é uma ilusão sobre a qual se baseia, erroneamente, a religião e a moral.

A ideologia fomenta a ideia de que é a consciência que determina a vida (Ricoeur, 1991: 180). Marx salientou que é o contrário, i.e. não é a consciência que determina a vida, mas a vida que determina a consciência (Marx, 1982: 531; Marx \& Engels, 1982: 26). Segundo a aceção negativa de ideologia, o que os indivíduos pensam é um produto da 
sociedade em que vivem (Ricoeur, 1991: 167). Os conteúdos ideológicos da consciência não possuem substantividade própria, porque as ideologias visam ocultar, desfigurar, sublimar a existência real. Por isso, são alienações.

Este sentido primordial de "ideologia" está na conceção do Capital de Marx: as pessoas não sabem o que fazem nem que participam no sistema. O conceito de ideologia implica "uma ingenuidade constitutiva: o não reconhecimento de seus próprios pressupostos, de suas próprias condições eficazes, uma distância, uma divergência entre a chamada realidade social e a nossa representação distorcida, a nossa falsa consciência da realidade" (Zizek, 2008: 24).

Segundo esta perspetiva marxista, a ideologia pode designar qualquer coisa. Em Um Mapa da Ideologia, Slavoj Zizek sublinhou que a ideologia "parece surgir exactamente quando tentamos evitá-la e deixa de aparecer onde claramente se esperaria que existisse" (Zizek, 2010: 7). Todas as formas de manifestação da ideologia implicam um modo de alienação; são sistemas abrangentes de pensamento coletivo. Para $A$ Ideologia Alemã, de Marx e Engels, as ideologias possuem um efeito conservador para justificarem as relações existentes de dominação e subordinação.

As formas de vida/cultura populares e visuais são ideológicas quando recorrem a imagens com significados ocultos, conotativos e já pensados, i.e. quando as suas imagens que nos fazem pensar não pensam. Este paradoxo, o da imagem que faz pensar e que não pensa, segundo Régis Debray (1994: 318) reforça o poder da imagem em evocar significados de forma indireta e em criar mundos possíveis. Todavia, existe sempre um fosso entre a imagem e a realidade, apesar de Régis Debray reconhecer o paradoxo da fusão indiscernível entre a imagem e a realidade: "O paradoxo é que imagem e realidade tornam-se indiscerníveis: um tal espaço é explorável e impalpável, ao mesmo tempo, não ilusório e irreal" (Debray, 1994: 278). Ao visível não corresponde necessariamente o real nem o verdadeiro. Contra esta fácil e errada correspondência, Régis Debray criticou o que designou por "equação da era visual". Na atual mediasfera (a videosfera, posterior à logosfera e à grafosfera, segundo a evolução técnica do ser humano), o visível impera por via das imagens, mas estas não devem ser confundidas com os próprios objetos nem, por conseguinte, com o real nem com o verdadeiro. Segundo Régis Debray, "somos a primeira civilização que pode julgar-se autorizada, por seus aparelhos, a acreditar em seus olhos", i.e. "a primeira a ter colocado um sinal de igualdade entre visibilidade, realidade e verdade", quando a imagem impede de ver (Debray, 1994: 358).

Segundo Umberto Eco, os sistemas de significação dependem da partilha pela comunicação, i.e. pela sujeição a um sistema de convenções comunicativas. Para consegui-lo, é necessário que "o sistema de saber se torne sistema de signos: a 
ideologia é reconhecível quando, socializada, se torna código" (Eco, 2001: 84). O sistema de saber corresponde aos conhecimentos partilhados, enquanto o sistema de signos corresponde ao código partilhado. Assim, com estes dois sistemas partilhados, a ideologia torna-se socializada e conotada, "simplificadora e esquemática", segundo Paul Ricoeur (1990: 69). "O aparato sígnico remete ao aparato ideológico e vice-versa", de acordo com Eco (2001: 85), tornando-se importante reconhecer quer a relação entre os códigos e as mensagens quer a relação das mensagens com as ideologias que se ocultam através da retórica.

Um determinado modo de empregar a linguagem identifica-se com um determinado modo de pensar a realidade e a sociedade, gerando ideologias e conotações ideológicas. A ideologia cria a retórica, por um lado, e a retórica cria a ideologia, por outro lado. Nas relações entre a retórica e a ideologia, "os códigos são sistemas de expectativas no universo dos signos", enquanto "as ideologias são sistemas de expectativas no universo do saber" (Eco, 2001: 86). Apesar de a ideologia não ser significado, ao traduzir-se em sistema de signos, "a ideologia passa a fazer parte dos códigos como significado daqueles significantes" (Eco, 2001: 87). A ideologia é uma forma de significado conotativo; é "a conotação final da totalidade das conotações do signo ou do contexto de signos" (Eco, 2001: 87).

$\mathrm{Na}$ relação entre a retórica e a ideologia, o paralelismo imediato surge com uma outra relação entre a comunicação e a cultura, i.e. a comunicação está para a cultura como a retórica está para a ideologia. Para Umberto Eco, a técnica publicitária parece assente no pressuposto de que "um anúncio mais atrairá a atenção do espectador quanto mais violar as normas comunicacionais adquiridas" e subverter um sistema de expectativas retóricas (Eco, 2001: 157). Seguindo vários códigos (iconográficos, de gosto e sensibilidade, retórico, etc.), a imagem publicitária baseia-se na proposta de arquétipos de gosto que preenche expectativas e oferece, por exemplo, "um produto feminino através da imagem de uma mulher dotada de todos os atractivos reconhecidos na mulher pela sensibilidade corrente" (Eco, 2001: 157).

No caso particular da imagem religiosa, esta conota sempre mais do que aquilo que representa e expressa objetivamente. A imagem de Cristo na Cruz, por exemplo, é mais do que uma imagem; é uma representação simbólica de toda a essência do Cristianismo. O poder da imagem de Cristo na Cruz é o poder de sintetizar e manifestar a essência do sagrado e do transcendente que, por natureza, é inefável. Para Jesús Casás Otero (2003: 94), se a imagem religiosa não expressar ou não puder representar a glória de Deus ou não permitir perceber o seu significado transcendente, tratar-se-ia de uma pura idolatria e não de um culto estético-religioso, porque a beleza intramundana não justifica o culto iconográfico. As imagens sacras são os símbolos representativos 
de um culto e, por isso, são vividas de um modo centralizador do culto e conforme a narrativa mítica. Assim também acontece com os arquétipos, modelos ou padrões culturais. Para Jung (2008: 448), um arquétipo representa os conteúdos do inconsciente coletivo. Seguindo esta perspetiva junguiana, as imagens e símbolos ancestrais presentes nas tradições e que são modelos endógenos de condutas e produções imaginativas (Chevalier \& Gheerbrant, 1997: 14). Segundo Eliade, é a presença das imagens e dos símbolos que conservam e mantêm "abertas" as culturas: "as imagens constituem 'aberturas' face um mundo trans-histórico (...) graças a elas podem comunicar-se as diversas 'histórias'” (Eliade, 1979: 187).

Nas imagens que servem como discursos públicos (e.g. na publicidade), a relação entre a retórica e a ideologia é, por conseguinte, estreita. As imagens possuem mais do que palavras e imagens; possuem valores, significados, conceitos, conotações e ideologias. As imagens dizem o que devemos ver, acreditar e pensar. As pessoas aderem à ideologia porque esta fornece identidade coletiva e consolo social. Todavia, as imagens revelam um paradoxo da visibilidade: as imagens no espaço público mostram tanto através de uma imagem única e esta oculta os sentidos ideológicos do que transmitem. Esta é a questão central da conotação ideológica. A imagem causa impacto porque tem poder (pelo menos o conteúdo que possui e expõe). O problema está nesta função da imagem, que não é sempre evidente e percetível.

O conteúdo ideológico não é explicitamente legível, porque é uma ausência, está no implícito, é dito no "não dito". Torna-se assim capaz de construir com eficácia e subtileza uma representação. A exploração do poder das imagens deve-se à tendência em usar apenas uma imagem e um tema, obedecendo à lógica ou estratégia sintética de motivação e apelo direto.

Através da transitividade semântica das imagens identifica-se uma fusão indiscernível entre a própria imagem e a realidade. No caso da publicidade, os discursos têm a pretensão de substituir a realidade pela imagem (Finkelstein, 2007: 153). Esta pretensão é ideológica, porque corresponde ao sentido de formação de uma consciência ingénua, alienada ou falsa sobre o que é a realidade e o que é a imagem enquanto mero analogon da realidade. Todavia, esta pretensão justifica o conceito e o sentido de ideologia (enquanto uma consciência ingénua ou alienada) que se aplicam às formas de vida populares e visuais do mundo contemporâneo. Demonstra-o o papel dos media e das imagens da publicidade: os media produzem discursos públicos e criam/mantêm determinados mitos a circular na sociedade. O mito nos media é um fator de alienação ideológica, porque o mito é uma fabricação da cultura de massas e serve de mecanismo ideológico para camuflar outras pretensões. O poder da imagem na publicidade é o poder do seu funcionamento e utilização enquanto dispositivo mitopoiético, i.e. 
dispositivo produtor e reprodutor de mitos e de significados míticos ou ideológicos que aparecem camuflados na mensagem que é difundida.

O que é o mito? Qual é o lugar do mito na atual cultura popular e visual? Um mito é uma conceção mental coletiva que assume a forma de um discurso, narrativa ou mensagem geral sobre algo que é considerado importante, mas que é, também, suscetível de fornecer uma explicação sobre o real (e.g. de fenómenos naturais ou de comportamentos humanos). Um mito é um sistema de representação psíquica ou mental da realidade; um sistema cultural partilhado por todos os membros de uma dada comunidade. Um mito confunde-se facilmente com uma narrativa fabulosa construída social ou popularmente. É, por conseguinte, uma elaboração imaginativa do espírito coletivo; uma alegoria ou representação metafórica de uma situação tomada como exemplar e, por isso, admitida por todos os que a sustentam e a partilham. Através do mito expõe-se algo de uma forma representativa e irrealista, porque o mito esconde sempre algo.

O lugar do mito nos discursos publicitários é o da distorção ideológica, i.e. é o lugar da mentira, o lugar de um certo sentido sobre a realidade (e.g. o mito da "eterna beleza e juventude" nas mensagens publicitárias, que dependem da imagem para mostrar modelos e fazer acreditar). O mito esconde ou exprime a "verdade" de uma determinada ideologia. As funções do mito na publicidade são determinantes na produção de segundos sentidos (ideológicos e culturais). Por norma, o mito tem uma função sincrética, porque funde ou combina vários elementos ou aspetos culturais da realidade. O mito associa-se naturalmente à ideologia, na medida em que esta constitui um sistema de ideias, valores e princípios que definem uma determinada visão da realidade e que orientam a forma de agir das pessoas que a seguem.

\section{Conclusão}

Qualquer linguagem pode "mascarar o pensamento", segundo a expressão de Wittgenstein (1999: 4.002). A imagem é, entre todas as formas de linguagem, o melhor exemplo para demonstrar a máscara do pensamento porque a imagem joga entre uma presença que se manifesta e uma ausência que se oculta. Considerando a propriedade visível ou o conteúdo ideológico e hiperbólico de uma imagem, bem como a sua forma tautológica e a ubiquidade com que se fazem notar, as imagens mascaram formas de pensar, mas desvelam formas de vida/cultura, no sentido em que ditam os modos de ver sem o revelar explicitamente. Esta é a principal ideia desenvolvida pelo presente texto: a imagem como ausência de uma outra presença, ocultação do visível, hierofania de significados. 
A complementaridade entre a sociedade de massas e a comunicação de massas (discursos públicos através de imagens) justifica a contemporânea idolatria pela imagem e a emergente vivência e convivência num espaço global e ressemantizado. É assim que a imagem adquiriu um centralismo nos usos e práticas sociais de transmissão de informações, tornando o visual ou a visualidade mais importante do que a própria visão, devido à ubiquidade dos ecrãs e das próprias imagens.

No tempo e no espaço atuais, as imagens funcionam como "cavalos de troia", i.e. são intrusivas e disseminadoras de significados. As imagens publicitárias no espaço urbano, por exemplo, permitem leituras caracterizadoras das pessoas e dos contextos sociais e culturais onde se inserem. Se Giorgio Agamben (1993: 64) afirmou que "o que impede a comunicação é a própria comunicabilidade", porque "os homens estão separados por aquilo que os une", as imagens que, no espaço público, passam de uma plêiade para uma pletora são o que impede a própria visibilidade, cujos significados tanto se revestem de presença como de ausência. Assim acontece porque uma imagem é, acima de tudo, uma hierofania; uma ausência que também está presente na forma retórica e na forma ideológica.

\section{Bibliografia}

Agamben, G. (1993). A Comunidade Que Vem. Lisboa: Editorial Presença.

Aumont, J. (2002). A Imagem. São Paulo: Papirus Editora.

Barthes, R. (1987). A Aventura Semiológica. Lisboa: Edições 70.

Barthes, R. (1991). Mythologies. Nova lorque: The Noonday Press.

Barthes, R. (2006). A Câmara Clara. Lisboa: Edições 70.

Barthes, R. (2007). Elementos de Semiologia. Lisboa: Edições 70.

Barthes, R. (2009). O Óbvio e o Obtuso. Lisboa: Edições 70.

Baudrillard, J. (1991). Simulacros e Simulação. Lisboa: Relógio d’Água.

Berger, J. et al. (2005). Modos de Ver. Barcelona: Editorial Gustavo Gili.

Bignell, J. (2002). Media Semiotics. Manchester: Manchester University Press.

Bulmer, S. \& Oliver, M. B. (2006). Visual rhetoric and global advertising imagery.

Journal of Marketing Communications, Vol. $12 \mathrm{~N}^{\circ} 1,49-61$.

Chevalier, J. \& Gheerbrant, A. (1997). Dicionário dos Símbolos. Lisboa: Círculo de Leitores.

Debord, G. (1995). The Society of the Spectacle. Nova lorque: Zone Books.

Debray, R. (1994). Vida e Morte da Imagem: Uma História do Olhar no Ocidente. Rio de Janeiro: Vozes.

Deleuze, G. (1985). Cinema 2: L'image-Temps. Paris: Les Editions de Minuit.

Derrida, J. (2005). A Farmácia de Platão. São Paulo: Editorial lluminuras. 
Eco, U. (2001). A Estrutura Ausente. São Paulo: Editora Perspectiva.

Eliade, M. (1979). Imágenes y Símbolos - Ensayos sobre el Simbolismo MágicoReligioso. Madrid: Ed. Taurus.

Eliade, M. (1999). O Sagrado e o Profano - A Essência das Religiões. Lisboa: Livros do Brasil.

Finkelstein, J. (2007). The Art of Self Invention - Image and Identity in Popular Visual Culture. Nova lorque: I.B.Tauris.

Fulchignoni, E. (1969). La Civilisation de l'Image. Paris: Payot.

Joly, M. (2008). Introdução à Análise da Imagem. Lisboa: Edições 70.

Jung, C. (2008) Tipos Psicológicos. Barcelona: Edhasa.

Marx, K. (1982). Para a Crítica da Economia Política. In Obras Escolhidas de Marx e Engels, $1 .^{\circ}$ Volume, Lisboa: Editorial Avante.

Marx, K. \& Engels, F. (1982). A Ideologia Alemã. In Obras Escolhidas de Marx e Engels, 1. ${ }^{\circ}$ Volume, Lisboa: Editorial Avante.

Nietzsche, F. (1995). Da Retórica. Lisboa: Vega.

Otero, J. C. (2003). Estética y Culto Iconográfico. Madrid: Biblioteca de Autores Cristianos.

Platão (1992). Ménon. Lisboa: Edições Colibri.

Platão (2000). Fedro. Lisboa: Guimarães Editores.

Platão (2006). A República. Lisboa: Fundação Calouste Gulbenkian.

Ricoeur, P. (1990). Historia y Verdad. Madrid: Ediciones Encuentro.

Ricoeur, P. (1991). Ideologia e Utopia. Lisboa: Edições 70.

Ricoeur, P. (2013). A Simbólica do Mal. Lisboa: Edições 70.

Sartori, G. (2000). Homo Videns - Televisão e Pós-pensamento. Lisboa: Terramar.

Sartre, J.-P. (s.d.). A Imaginação. Lisboa: Difel.

Schopenhauer, A. (2005). O Mundo como Vontade e Representação. Porto: Rés Editora.

Sontag, S. (2012). Ensaios de Fotografia. Lisboa: Quetzal.

Volli, U. (2004). Semiótica da Publicidade. Lisboa: Edições 70.

Wittgenstein, L. (1996). Philosophical Investigations. Oxford: Blackwell.

Wittgenstein, L. (1999). Tractatus Logico-Philosophicus. Londres: Routledge.

Zizek, S. (2008). The Sublime Object of Ideology. Londres: Verso.

Zizek, S. (org.) (2010). Um Mapa da Ideologia. Rio de Janeiro: Contraponto Editora. 
Paulo Barroso tem pós-doutoramento em Ciências da Comunicação pela Universidade do Minho e doutoramento em Filosofia da Linguagem pela Universidade de Santiago de Compostela. É licenciado e mestre em Ciências da Comunicação e em Filosofia. É professor adjunto na Escola Superior de Educação de Viseu e investigador integrado no Centro de Estudos de Comunicação e Linguagens da Faculdade de Ciências Sociais e Humanas da Universidade Nova de Lisboa.

$\bowtie$ pbarroso1062@gmail.com 